\title{
A Book Report of Introducing English for Academic Purposes
}

\author{
Wei WU \\ North China University of Technology, Beijing, China
}

\begin{abstract}
Maggie Charles and Diane Pecorari's (2016) Introducing English for Academic Purposes is a very good book for specialized language, covering EAP's research in scope, planning and teaching, and evaluation and the issues are profound and clear. From the extension of language research to the formulation of policy, it can be described as novel and unique. It sums up the research contents and opinions in detail in the article.
\end{abstract}

Keywords: EAP, planning, academic

\section{Introduction}

Introducing English for Academic Purposes is one book in a set of English for Specific Purposes. This book extensively introduces an important area of growing development in English teaching-academic English, English for Academic Purposes (EAP), Covering EAP's global and institutional status, EAP planning and teaching, and research performance around the world. The purpose of academic English is to help English learners develop their skills in English through learning.

The writing of this book combines the knowledge of the very diverse context of teaching EAP around the world, designed for readers from many different backgrounds. Readers can not only feel immersed when they are reading this book, but also have the opportunity to understand some useful corpus and Internet information or other more useful resources.

The contents of the book are divided into three parts, twelve chapters, which concerned about different aspects of EAP in each chapter. The first section discusses to provide EAP teaching in the context, the field of EAP. The second section discusses the planning and preparation of EAP process and it is essential for those who develop courses to understand this process. The third section provides the relevant terms of EAP, including the main types of academic texts which are taught and the way in which courses are evaluated. The introduction of this book provides a direction for the readers to help them find the best way to use this book for their professional development.

The design of this book can be described as very humanized. In the reading process, readers can select the part of their own need to read or learn and do not have to follow the order to read. If you encounter the terminology you are not familiar with, the author also attached a glossary of terms for readers to reference at the end of the book. In order to draw the attention of the readers and help them to fully understand, the terminology listed in the glossary of terms in the first reference in each chapter is highlighted in bold, we can see the author considers very detailed things for readers. In addition to the glossary above, each chapter of this book contains several parts- "thinking", "task", "reflection", and "further reading and resources". The purpose of "thinking" which is at the beginning of each chapter is to give readers more room for thought; not only that,

Wei WU, lecturer, M.A., Department of Teaching Chinese as a Foreign Language, North China University of Technology. 
there will be "task" interspersed in the various points in each chapter, so that readers can combine theory and practice; in order to deepen the reader's impression, there will be "reflection" part at the end of each chapter, so that readers can have the opportunity to review the main content of that chapter once again; finally, in order to enrich the study of the reader, it also lists a series of "further reading and resources" document at the end of each chapter that allows the reader to continue reading, learning, researching, and thinking. These features are designed to help readers make better use of this book.

From this book, the overall framework of EAP is: demand analysis-developing learning objectives-curriculum design.

After reading each chapter, the composition structure of each chapter is as follows: the contents or/and the purpose of this chapter — cause thinking — point of view and task proposed—list examples, practice profiles, the corresponding tasks assigned—cause reflection— provide further reading and resources.

\section{Introduce the Contents of Each Chapter}

Part I: EAP field, including 1-3 chapters;

Part II: Planning EAP, including 4-6 chapters;

Part III: Teaching Evaluation EAP, including 7-12 chapters.

\section{Chapter 1 Scope of EAP}

There are many students, teachers, and researchers from different disciplines around the world. Even if they are not their mother tongue, they also use English for academic work so that the presence of academic English (EAP) will support them. This chapter focuses on four areas of academic English, which will provide readers with a good starting point to gain insight into EAP in later chapters. The four areas are: (1) the relationship between EAP and English teaching in other areas; (2) the activities of EAP practitioners; (3) the nature of EAP; and (4) the various questions and concepts involved in EAP practitioners.

\section{Chapter 2 the Global Background of EAP}

English plays an important role in the world and because higher education is one of the departments that use English, so EAP is a global undertaking career. However, the status of English is different from the context: For example, some people learn English as a foreign language, while others use English as a second language; in addition, the amount of using English in their environment by the learners is also different. These factors in turn greatly affect how EAP should be taught in detail.

The purpose of this chapter is to describe the rise of English in academic contexts and to describe many of the different settings that EAP is taught and the impact of these settings on teaching. At the end of this chapter, readers will understand how their teaching adapts to the grand picture of global EAP practice. This chapter focuses on the four parts: (1) English as a common language; (2) English media teaching; (3) EAP settings and participants: EAP teaching revelation; and (4) global EAP issues.

\section{Chapter 3 the Institutional Background of EAP}

Like all teaching, the core of EAP is the learning experience that takes place inside and outside the classroom and the interaction between the student and the teacher. However, this core activity takes place in the organizational framework of universities or other educational institutions as well as in the teaching practice of organizing and managing realistic scenarios. As a classroom teacher, the administrative decision restricts the teacher's teaching and the teacher's ability to influence them limitedly. However, if teachers understand their 
system formation and reasons, they will be able to better provide background support for EAP to achieve the best guidance.

Policy and administrative practices vary by country and institution and the purpose of this chapter is to outline the factors that managers often decide or indirectly influence. This chapter describes five key areas where administrators make choices: EAP curriculum provision, student enrollment, staffing, funding, and organizational structure. The discussion is divided into six sections to demonstrate and describe: (1) EAP course provided; (2) students in the EAP program; (3) EAP teachers; (4) how EAP teaching is funded; (5) EAP organization; and (6) EAP status.

\section{Chapter 4 Methods for Providing Information to EAP}

This chapter focuses on ways to provide information for research and teaching in the EAP field. The content includes: (1) approach based on corpus-based; (2) method based on type (or genre); (3) method based on social context; and (4) the choice of method, that is, to determine which method or method combination will be suitable for their own teaching environment.

\section{Chapter 5 Planning EAP Terms and Conditions}

This chapter is about planning and developing EAP terms. Of course, not all courses are designed from scratch; many teachers have inherited courses that others plan or must belong to certain scheduled parameters. However, it is useful to understand that the entire development process will allow the planner to make effective choices wherever possible, so the author describes the entire planning process from start to finish. The main contents include: (1) how to carry out need analysis; (2) how to develop learning objectives; and (3) how to choose the relevant and appropriate content for curriculum design.

\section{Chapter 6 EAP Materials}

Need analysis is at the heart of EAP teaching and is particularly relevant to the production of materials, as this is the key to their choice and development. The purpose of this chapter is to explore the choice of commercial publishing materials or materials prepared by teachers themselves. This chapter describes the advantages and disadvantages of both types of materials. By reading this chapter, the reader can know the principles behind the material for selecting and adapting materials and writing what they are involved in.

\section{Chapter 7 Academic Discourse}

In this chapter, the author will focus on the specific aspects of EAP teaching, mainly to solve "what is academic discourse" and "how to teach". After reading this chapter, the reader will understand what the academic discourse is and what may be the main discourse feature that can cause problems for EAP students. This knowledge will help teachers make decisions about the choice of text and the choice of discourse or practice in the classroom. The authors describe four factors that affect differences of academic discourse: (1) differences in registration; (2) differences between spoken and written discourse; (3) differences in discipline; and (4) differences in genre.

\section{Chapter 8 Academic Vocabulary}

Vocabulary is a key area of language learning, but EAP teachers often find it difficult to know what vocabulary their students need and use as one of the key areas of their concern. The main purpose of this chapter is to examine the nature of the vocabulary required by EAP students and to emphasize the learning and teaching process that supports successful vocabulary acquisition. This chapter deals primarily with how the 
various types of lexicon items are distinguished and which vocabulary should be taught in the teacher's specific context as well as the methods that can be used. The author also made an introduction in the text about how the teachers teach vocabulary.

\section{Chapter 9 Written Professional Genre}

This chapter provides a direction for what is called "professional genre" and the author makes a brief description of the professional genre and the differences between these genres in different disciplines. The main contents of the article include what is the basic professional genre, their characteristics and their use in different disciplines, and how to help students achieve their reading purposes. The author divides the genre into the genre of the teaching process (e.g., the thesis, the answer to the examination) and the research process. With regard to the question of teaching professional genres, the author believes that the following three areas of teaching can be used to create special value for learners: (1) to understand the nature of professional genre; (2) to understand the purpose of reading professional genre; and (3) to make the text accessible.

\section{Chapter 10 Written Learners Genre}

The main content of this chapter is about the genre that students must write. The author first analyzes and describes genres that most of the undergraduate and graduate use and then discusses the methods that need to be used in teaching and learning academic writing. At the end of this chapter, the reader will be familiar with some of the major learner genres and be able to make informed decisions, which genres will be taught and which teaching options will suit their background.

\section{Chapter 11 Speech Genre}

In this book, the author emphasizes the writing genre that is very important to academic achievement, but the control of oral proficiency also occupies a large share of student success. In this chapter, the author focuses on listening, lectures, listening comprehension, and the teaching of notes as well as oral speaking and lectures. After reading this chapter, readers will know the structure of the lecture, the difficulties brought about in the listening and taking notes, and the good evidence base for teaching in these areas. In the context of speaking, we will know what a successful speech is and how to encourage active participation in seminars and discussions.

\section{Chapter 12 Evaluation and Feedback in EAP}

Assessment is a universal feature of higher education and it is a broad concept that includes testing, writing assignments, oral presentations, and any other forms that allow information on students' achievement to be measured. This chapter focuses on the assessment methods commonly used in the EAP background as well as the mechanisms behind the best known diagnostic measures. In addition, some common assessment forms are introduced, such as the factors that have the greatest impact on feedback and how to build feedback and assessment to address particularly difficult problems-plagiarism.

\section{Understanding}

"Language is a long history of art, it comes with the generation of human society. With the development of society, the way people think, the improvement of cognitive ability, language is also increasingly rich and perfect" (LU, 2010, p. 121). The special purpose language embodies this feature. Hutchinson showed a picture of a tree, "The branches just below this level indicate that these may conveniently be divided into two main types of ESP differentiated according to whether the learner requires English for academic study or for 
work/training" (Hutchinson \& Waters, 1987, p. 16). "Another typical tree diagram for ESP divides EAP and EOP according to discipline or professional area" (Dudley-Evans \& St. John, 1998, p. 6). There are some other scholars on the ESP (English for Specific Purposes) classification, which are not listed here one by one. The point is that these ESP classes contain EAP, which shows that EAP is an important part of ESP. This book has a comprehensive introduction to EAP, enriches the contents of ESP and opens up a new field of language research; after reading the book, I have a little understanding about some of the contents of the third, fourth, and sixth chapters. The administrator's function mentioned in Chapter 3 is:

A third administrative function is ensuring that all teachers have good opportunities for professional development. This too is something which is often neglected in many units of language teaching, but is especially important in EAP, so that staff from disciplinary backgrounds have the opportunity to learn about language teaching, and vice versa. (Charles, 2016, p. 35)

As a teacher of Chinese as a foreign language, I am in favor of this view of the author very much, because when teaching EAP, language teachers are basically no subject of professional background, they may be not accurate on EAP core vocabulary, fixed expression, etc., which caused a lot of teachers only to be mechanical in accordance with the teaching materials for lesson preparation. In fact, there are a lot of contents which are collected through the search materials other than the relevant information by the teachers who use professional knowledge to refine and summarize, which is the effective complement to the content of the textbook. If the teacher does not understand the subject of professional background knowledge, it is difficult to explain the content completely and comprehensively. On the other hand, if the professional subject teachers do not understand the linguistic knowledge, they will not be able to grasp the language difficulties of the students' disciplines, such as vocabulary, because the professional subject teachers do not know where the problem lies. Only these two types of teachers carry on the complementary, each other can make up for the problems that arise in EAP. Therefore, it is an important aspect that the administration needs to support to ensure that teachers have the opportunity to carry out their career development.

When it comes to the corpus-based approach in Chapter 4, the author enumerates the four online free corpuses for EAP corpus, which fills the shortcomings of EAP corpus in China. When it comes to methods based on type (or genre), the author lists three methods, in which the language analysis method is quite impressive. This approach has gradually become the basis of many EAP researches for teachers and students to provide a useful tool. We should also make full use of this effective method in future research and strive for further breakthroughs in teaching and research.

Chapter 6 focuses on EAP materials. The author argues that in EAP, "commercial and self-developed, we must first examine the notion of authenticity, which underlies many decisions on materials' use and development" (Charles, 2016, p. 75). So what is "real"? The author of the book believes that authenticity includes the authenticity of the text, learners, teachers, and the task. I was very recognized this point of view. In real work, teachers sometimes complain that the textbooks are not suitable for the level of the students they teach; or the scenarios designed in the textbook rarely occur in reality; or the activities designed in the classroom are rarely seen in reality; even some of the feedback from the students, that is, the way that is learned from the classroom to communicate with the Chinese people is not the same with a lot of Chinese people and their expressions; or although the students have learned a lot of Chinese expressions, they still do not understand the Chinese people to express the meaning in their work and so on. The root cause of these 
circumstances is the failure to follow the principle of authenticity. Therefore, in order to reduce the occurrence of the above situation, not only the EAP material selection should be true, but also the topic of language teaching should be some authentic Chinese language expressions which are outside the textbooks.

\section{Evaluation}

The background of the EAP system in this book is an innovation, because in this area of the book, very few people take into account the views of the administration from this point of view and people will often ignore them. In this book, however, the author discusses the background of the system as a prerequisite for supporting EAP, since the author argues that administrative decisions limit the teaching of the teachers and that administrative staff will have an impact on EAP. It also inspires the future of the curriculum design before the preparation work not only to consider the factors that require student analysis, but also take into account the views of the executive.

The fifth chapter of the book is also a very important chapter, which can help readers understand the EAP framework, so that readers can grasp the overall composition of the various parts of EAP. But the demand analysis part of the book only mentioned the target scenario analysis, it seems not very comprehensive, which is what I think to be added more.

\section{Conclusion}

EAP, simply speaking, is for academic purposes and learning English and learners are people who are in the academic environment to use English. This means that learners' needs dictate EAP, from course development to material selection to event design and EAP research should all be done around the needs analysis. EAP not only requires linguistic teachers, but also needs teachers in the field of specialized disciplines, so it plays an irreplaceable role to establish a complementary team of teachers on the long-term development of EAP. EAP is not the same as general English teaching and there is a lot of room for research. Although this road is still very long, EAP provides interesting insights into language and knowledge sharing, so this area is a passionate burst of the field and is a worthy career to make further and deeper development.

\section{References}

Charles, M., \& Pecorari, D. (2016). Introducing English for academic purposes. Oxon: Routledge.

Duley-Evans, T., \& St. John, M. J. (1998). Developments in ESP: A multi-disiplinary approach. Cambridge: Cambridge University Press.

Hutchinson, T., \& Waters, A. (1987). English for specific purposes. Cambridge: Cambridge University Press.

LU, J. E. (2010). Reading report of language and culture. Journal of Popular Literature and Art, 19, 121. 